\title{
Influence of the geometric parameters of the electrical ring resonator metasurface on the performance of metamaterial absorbers for terahertz applications
}

\section{Citation for published version (APA):}

Gomon, D., Sedykh, E., Rodríguez, S., Idelfonso, T. M., Zaitsev, K., Vozianova, A., \& Khodzitsky, M. (2018). Influence of the geometric parameters of the electrical ring resonator metasurface on the performance of metamaterial absorbers for terahertz applications. Chinese Optics, 11(1), 47-59.

https://doi.org/10.3788/CO.20181101.0047

DOI:

10.3788/CO.20181101.0047

Document status and date:

Published: 01/02/2018

\section{Document Version:}

Publisher's PDF, also known as Version of Record (includes final page, issue and volume numbers)

\section{Please check the document version of this publication:}

- A submitted manuscript is the version of the article upon submission and before peer-review. There can be important differences between the submitted version and the official published version of record. People interested in the research are advised to contact the author for the final version of the publication, or visit the DOI to the publisher's website.

- The final author version and the galley proof are versions of the publication after peer review.

- The final published version features the final layout of the paper including the volume, issue and page numbers.

Link to publication

\footnotetext{
General rights

- You may freely distribute the URL identifying the publication in the public portal. follow below link for the End User Agreement:

www.tue.nl/taverne

\section{Take down policy}

If you believe that this document breaches copyright please contact us at:

openaccess@tue.nl

providing details and we will investigate your claim.
}

Copyright and moral rights for the publications made accessible in the public portal are retained by the authors and/or other copyright owners and it is a condition of accessing publications that users recognise and abide by the legal requirements associated with these rights.

- Users may download and print one copy of any publication from the public portal for the purpose of private study or research.

- You may not further distribute the material or use it for any profit-making activity or commercial gain

If the publication is distributed under the terms of Article 25fa of the Dutch Copyright Act, indicated by the "Taverne" license above, please 


\title{
Influence of the geometric parameters of the electrical ring resonator metasurface on the performance of metamaterial absorbers for terahertz applications
}

\author{
GOMON Daniel ${ }^{1}$, SEDYKH Egor ${ }^{1}$, RODRÍGUEZ Sebastián ${ }^{2}$, IDELFONSO Tafur Monroy ${ }^{2}$, \\ ZAITSEV Kirill $^{3}$, VOZIANOVA Anna ${ }^{1}$, KHODZITSKY Mikhail ${ }^{1}$ \\ (1. ITMO University, Saint Petersburg,197101,Russia; \\ 2. Eindhoven University of Technology, Eindhoven, The Netherlands; \\ 3. Bauman Moskow State Technical University, Moscow 105005 ,Russia) \\ *Corresponding author,E-mail:i.tafur.monroy@tue.nl
}

\begin{abstract}
In this paper, the effect of the geometrical parameters of an electrical ring resonator(ERR) on the total absorptivity of metamaterial absorbers is analyzed. In particular, the effect of electrical ring resonator parameters, dielectric layer(spacer) thickness and electrical ring resonator thickness on the absorber of metamaterials are analyzed in detail. On this basis, the orthogonal experiment is set up to analyze the combined effects of several parameters and finally obtain the theoretical absorptivity of metamaterials. Based on the above results, the principle prototype of two metamaterial absorbers is prepared. The results show that the narrowband absorptivity of the prototype is higher than $98 \%$, which provide guidance for the design of high performance absorber.
\end{abstract}

Key words : metamaterials ; spectroscopy ; terahertz; absorbers

\section{电环形谐振腔表面几何参数对太赫兹 超材料吸收体性能的影响}

GOMON Daniel ${ }^{1}$, SEDYKH Egor ${ }^{1}$, RODRÍGUEZ Sebastián ${ }^{2}$, IDELFONSO Tafur Monroy ${ }^{2}$, ZAITSEV Kirill $^{3}$, VOZIANOVA Anna ${ }^{1}$, KHODZITSKY Mikhail ${ }^{1}$

(1. ITMO 大学, 圣彼得堡, 197101, 俄罗斯;

2. 埃因霍温技术大学, 埃因霍温, 荷兰;

3. 鲍曼莫斯科国立技术大学, 莫斯科, 105005 , 俄罗斯)

摘要: 本文分析了电环形谐振腔的几何参数对超材料吸收体吸收率的影响。文中详细分析了电环形谐振腔参数、介电层 (间隔物) 厚度和电环形谐振腔厚度对超材料吸收体的影响, 在此基础上, 设置正交实验分析了几种参数的综合影响, 最 
终获得超材料的理论吸收率。根据上述结果, 制备了 2 个超材料吸收体的原理样机, 经实验测得, 原理样机的窄带吸收 率高于 $98 \%$ 。本文的研究成果为高性能吸收器的设计提供了指导。

关 键 词: 超材料; 光谱;太赫兹; 吸收器

中图分类号：文献标识码:A doi : 10.3788/CO.20181101.0047

\section{Introduction}

Metamaterial devices for terahertz $(\mathrm{THz})$ frequency band have been a subject of close attention for the last decade. The reason behind this interest is the lack of natural materials with strong response to electromagnetic radiation of terahertz frequencies. Particularly there is a need for materials with strong absorption in terahertz frequency range for such applications as terahertz sensing, hyperspectral imaging and screening ${ }^{[1]}$. The pioneering paper on $\mathrm{THz}$ metamaterial absorbers ( MMA) based on electrical ring resonators $(\mathrm{ERR})$ has been published by Tao ${ }^{[2]}$ ( his colleague Landy studied the same structure for far infrared wavelength region $\left.{ }^{[3]}\right)$. The proposed MMA is based on the idea that a good metamaterial absorber must minimize both reflection, by matching the impedance of the structure to one of the surrounding medium, and transmission, by introducing a metallic array of cut-wires. A bilayer structure satisfying these requirements ${ }^{[2]}$ is composed of an array of ERRs ( two split-ring resonators placed back to back) separated by a polymide spacer and backed by an array of metal strips oriented parallel to the centerline of ERR. Such metamaterial could be called metasurface because its thickness is less than the wavelength. Such geometry of structure allows to tune the permittivity $\varepsilon(\omega)$ and the permeability $\mu$ $(\omega)$ of the metasurface. It can be done by changing the ERR geometry or varying the substrate thickness and the cut-wire geometry. This design can have theoretical absorptivity close to unity (0.99) with full width at half maximum(FWHM) of 4 percent of $\omega_{0}$. The authors verified this design by obtaining experimentally the absorptivity value of 0.7 at 1. $4 \mathrm{THz}$. Such a great difference between theoreti- cal and experimental results is explained by a variation of metasurface constitutive parameters from the tabular values and by the non-optimized fabrication process. The transmission line model for this design is discussed in Ref. [4]. Further the works on $\mathrm{THz}$ MAs have been continued in the following directions: designing of polarization-insensitive and incidence angle-insensitive structures; designing of multiband and broadband absorbers; designing of absorbers with tunable absorption and center frequency. In the next work Tao ${ }^{[5]}$ considered a metasurface-dielectric-ground plane structure which was fabricated on a flexible polyimide substrate and he experimentally obtained the absorptivity of 0.96 at 1. $6 \mathrm{THz}$. As can be seen from Ref. [5], the structure is sensitive to both angle of incident electromagnetic wave and its polarisation. For such structure the resonant peak frequency experiences a blue shift as the angle of wave incidence increases. The first resonant absorption peak has greater absorptivity value and quality factor for TM polarization of radiation. Also it should be noted the presence of high frequency peak in the absorption spectrum. In 2009 year, Landy ${ }^{[6]}$ proposed another structure, an array of unit cells, which were comprised of two different cross-shaped resonators separated by a dielectric spacer $^{[6]}$. This MMA had experimental absorptivity of 0.75 at $1.15 \mathrm{THz}$. This structure is polarizationinsensitive due to the symmetry of the unit cell. In 2010 year, Ye et al. ${ }^{[7]}$ performed the numerical simulation of absorption spectrum of a single band MMA with a unit cell composed of both cut-wire (polarization sensitive) and cross-shaped (polarization insensitive) resonators backed by a metallic ground plane with a dielectric spacer, it was shown that the structure has good wide angle absorption. The structure had the simulated absorptivity of 0.98 at 4.96 
THz. Same year, Shchegolkov et al. ${ }^{[8]}$ published the paper with the numerical simulation results on the same structure and with experimental results on the similar structure with an unit cell composed of a metasurface which is an array of holes complementary to the cut-wires with cross-shaped resonators, backed by the metallic ground plane with the dielectric spacer. Despite having near unity absorptivity (greater than 0.97 for angles up to $70^{\circ}$ ) the complementary structure has one significant drawback: its center frequency of absorption peak redshifts by a decade comparing to the unit cell composed from the cross-shaped resonators ${ }^{[8]}$. Interest towards multiband MMAs has also been sparked. In 2010 year, Tao et. al. ${ }^{[9]}$ published the paper on a dual band absorber which had two peaks of absorptivity of 0.85 at $1.4 \mathrm{THz}$ and 0.94 at $3.0 \mathrm{THz}$. This MMA had a unit cell comprised of two electric field coupled (ELC) resonators combined into a single resonator $^{[9]}$. In 2011 year, Shen et al. ${ }^{[10]}$ proposed similar MMA designs with an unit cell comprised of concentric square-ring resonators backed by a layer of metal and spaced by a dielectric layer. In the context of Ref. [10], this structure acts like a multiband absorber having three absorption peaks equal to the number of the square ring resonators ${ }^{[10]}$. This design is polarisation-insensitive and gives absorptivity values of $0.99,0.96$, and 0.98 at $4.02 \mathrm{GHz}$, 6. $75 \mathrm{GHz}$ and $9.24 \mathrm{GHz}$ respectively. Multilayer absorbers (composed of 3 metasurfaces and a ground plane separated by dielectric layers) and supercell absorbers with an unit cell comprised of several resonators, both based on the metasurfaces composed of the cross-shaped resonators have also been studied by Grant ${ }^{[11]}$. The paper draws a comparison between multilayer and superpixel structures (the latter being more technological in a sense of fabrication: layered structures require several fabrication steps and sometimes there is a need for the precise mask alignment for the photolithography process, which greatly adds to manufacturing time and cost and it can potentially have greater variation of its geometric parameters due to defect and error accumulation during the fabrication process). This work states that the superpixel structure has a disadvantage of being some polarization dependence and having lower absorption than the multilayer structure $(0.5$ versus 0.6$)$, though it has greater bandwidth than the multilayer MMA bandwidth (2.18 THz versus $1.86 \mathrm{THz}$ ). Another interesting idea to implement a dual-band absorber was proposed by Wang et al. ${ }^{[12]}$ : the dual-band MMA ( the metasurface-dielectric-metallic ground plane structure) with a cut-wire metasurface unit cell ${ }^{[12]}$. The high-order resonance of the cut-wire was used to obtain the second absorption band of the high quality factor $(Q=8.4)$. The simulation results give the absorptivity of 0.9967 and 0.9973 at 1. $42 \mathrm{THz}$ and $2.99 \mathrm{THz}$ with FWHM of $0.2 \mathrm{THz}$ and $0.05 \mathrm{THz}$ respectively. It is reported that the amplitude of the high-order absorption peak significantly changes with the background medium permittivity, which can be used in biosensing applications.

This work is devoted to investigation of ERR metasurface parameters such as the unit cell geometric parameters to obtain perfect absorption in the frequency range of $0.25-1.75 \mathrm{THz}$. So the development of an ideal absorber for $\mathrm{THz}$ spectroscopy and imaging using metamaterial resonant elements takes particular interest of scientific community nowadays, also it's a promising candidate for selective reflective mirrors for $\mathrm{THz}$ narrowband absorption, that has a negative influence on biological objects.

\section{Description of the structure}

The structure studied in this paper is a MMA with a unit cell based on ERRs, typically used in the implementation of narrowband absorbers. This structure consists of 4 layers: 1 is the silicon substrate, 2 is the reflective copper film, 3 is the dielectric spacer, 4 is the ERR copper array.

The ERR is composed by 2 split rings connect- 
ed to each other and is defined by the following parameters : $g$ is the gap of the ERR; $w$ is the width of the stripes; $a, b$ are the length and the width of the ERR, respectively; $p$ is the distance between the ERR boundary and the unit cell border. The structure is shown in Fig. 1.

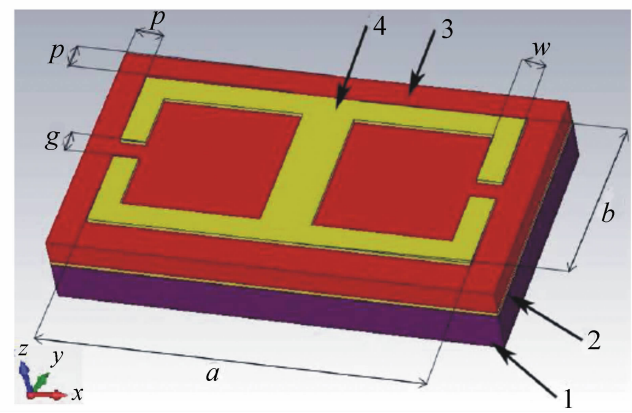

Fig. 1 MMA Structure. 1. the silicic substrate $(20 \mu \mathrm{m})$; 2. the copper reflective layer $(0.5 \mu \mathrm{m})$; 3. the dielectric spacer ( 12 $\mu \mathrm{m})$; 4. the copper $\operatorname{ERR}(0.5 \mu \mathrm{m})$

\section{Evaluation and design process}

To create a MMA with perfect absorptance, the evaluation process will find the optimal values for the ERR geometry and analyze the effects of different layers thicknesses. The silicon layer (the $1^{\text {st }}$ layer) is used only as the substrate during the fabrication process, so it won't impact the total absorptance; the copper layer(the $2^{\text {nd }}$ layer) has to reflect $100 \%$, thus its thickness has only to be greater than the skin depth. Only the thickness of the polyimide SU-8 spacer (the $3^{\text {rd }}$ layer) and the $\operatorname{ERR}$ (the $4^{\text {th }}$ layer) thickness will influence the MMA absorptance.

In order to make an independent analysis of the influence of each geometric parameter on the MMA performance, the evaluation process will be performed in the following 5 steps :

(1) Definition of the reference parameters: In this step the simulation process will be defined and the standard parameters to be used as reference will be defined, in order to prepare the simulation environment for the next steps of the process.
(2) Analysis of the ERR geometry influence: This step will define different sets for the ERR geometry in order to evaluate their effect on the final structure. From this step, a set of geometric parameters for the $\operatorname{ERR}(a, b, w)$ will be selected to be used in the optimization of the next steps.

(3) Analysis of the dielectric layer ( spacer) thickness: In this step, a parametric sweep of the spacer thickness will be performed. From the results the optimum spacer thickness will be selected.

(4) Analysis of the ERR thickness: The similar one as the previous step, a parametric sweep of the ERR thickness will be performed to obtain the ERR thickness optimal value.

(5) Final implementation: All the parameters will be included in a last optimization of the ERR geometry. The last results will be simulated to obtain the theoretical absorptance of the metasurface. The results obtained here will be used in the MMA prototypes fabrication process.

In each step, the MMA theoretical absorption was obtained in the frequency range of 0.25 1. $75 \mathrm{THz}$, using the simulation based on the finitedifference frequency-domain ( FDFD ) $\operatorname{method}^{[13]}$ with tetrahedral fragmentation. The electrical field was oriented in two directions in order to check the polarization dependence of the metasurface absorption : $\theta=0^{\circ}(y$-polarized wave $)$ and $\theta=90^{\circ}(x$-polarized wave). $\mathrm{x}$ - and $y$-polarized waves have different resonant frequencies because this structure isn' $t$ symmetrical in $x$ - and $y$-directions (but it allows to tune the resonant frequency by the sample rotation). For each case, the S-parameters were obtained to calculate the absorptance. When the transmission coefficient $T\left(T=\left|S_{21}\right|^{2}\right)$ is equal to zero, the absorptance depends on the reflection $R\left(R=\left|S_{11}\right|^{2}\right)$ as shown in Eq. (1) :

$$
A=1-R \text {. }
$$

\subsection{Definition of reference parameters}

As a first step in our study, the structure was 
designed using the standard set of layers thicknesses, which will be used as a reference in the different steps of the evaluation process. These layers thicknesses are shown in Tab. 1.

Tab. 1 Unit cell layer thickness

\begin{tabular}{ccc}
\hline Layer & Material & Layer thickness $/ \mu \mathrm{m}$ \\
\hline 1 & Silicon & 20 \\
2 & Copper & 0.5 \\
3 & Polyimide SU-8 & 12 \\
4 & Copper ERR & 0.5 \\
\hline
\end{tabular}

We used the typical value of the silicon permittivity of $\varepsilon=12$. The complex copper conductivity dispersion $\hat{\sigma}(\omega)$ was calculated using the Drude model $^{[14]}$, Eq. (2) :

$$
\hat{\sigma}=\frac{\varepsilon_{0} \varepsilon_{\infty} \omega_{\mathrm{p}}^{2}}{\gamma+\mathrm{i} \omega},
$$

where $\varepsilon_{0}$-the permittivity of free space, $\varepsilon_{\infty}=4.5$, the copper permittivity at infinite frequency, $\omega_{\mathrm{p}}=2$ $128 \mathrm{THz}$-the plasma frequency, $\gamma=4.35 \mathrm{THz}$-the electron relaxation frequency, $\omega$ is an angular frequency.

The polyimide SU-8 complex refractive index is shown in Fig. 2 and it could be calculated according to Eq. (3) :

$$
\begin{gathered}
\hat{n}(\omega)=n^{\prime}(\omega)+\mathrm{i} n^{\prime \prime}(\omega)= \\
n^{\prime}(\omega)+\mathrm{i} \frac{c \alpha(\omega)}{2 \omega},
\end{gathered}
$$

where $\hat{n}$ is the complex refractive index; $n^{\prime}, n^{\prime \prime}$ is its real and imaginary part respectively; $c$ is the speed of light in vacuum; $\alpha$ is the absorption coefficient.



Fig. 2 Dispersion of refractive $\operatorname{index}(1)$ and absorption coefficient(2) of SU-8

The polyimide complex refractive index dispersion was obtained experimentally using the standard time-domain terahertz spectroscopy ${ }^{[15]}$.

\subsection{Analysis of the ERR geometry influence}

To evaluate the ERR geometry influence, the ERR geometrical parameters were changed to generate different ERR metasurfaces. The sample 1 corresponded to the reference values, other samples were obtained by sweeping every $10 \%$ of the values in the sample 1. The total number of samples and the corresponding geometric parameters are shown in Tab. 2.

Tab. 2 Simulated MMA geometric parameters

\begin{tabular}{cccccc}
\hline MMA samples & $a / \mu \mathrm{m}$ & $b / \mu \mathrm{m}$ & $g / \mu \mathrm{m}$ & $p / \mu \mathrm{m}$ & $w / \mu \mathrm{m}$ \\
\hline 1 & 160 & 80 & 15 & 15 & 5 \\
2 & 176 & 88 & 15 & 15 & 5.5 \\
3 & 192 & 96 & 15 & 15 & 6 \\
4 & 208 & 104 & 15 & 15 & 6.5 \\
5 & 224 & 112 & 15 & 15 & 7 \\
\hline
\end{tabular}

The results of these first simulations ( 5 structures with the geometric parameters from Tab. 2 and the layers thickness given from Tab. 1) are presented in Fig. 3. They demonstrate relatively low ab- sorption of $\mathrm{THz}$ radiation, with absorptance no higher than $55 \%$. Tab. 3 summarizes the obtained resonant frequencies and their calculated absorptance. 




(a)

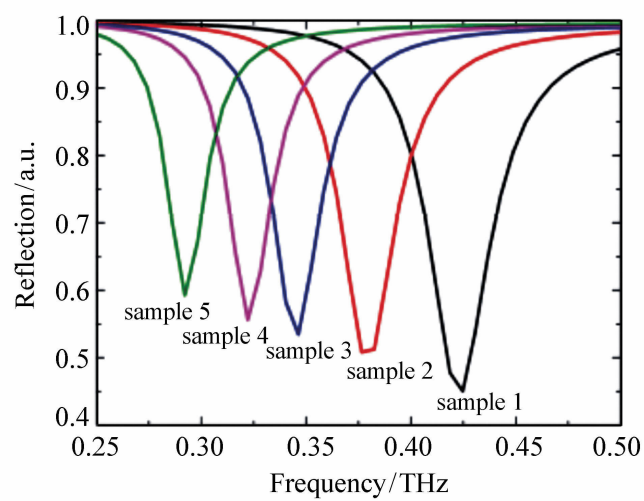

(b)

Fig. 3 Spectral characteristics of 5 samples with geometric parameters from Table 2 for $y$-polarized(a) and $x$-polarized(b) waves. The layers thicknesses are given from Tab. 1

Tab. 3 Simulated results for the 5 absorbers

\begin{tabular}{ccccc}
\hline \multirow{2}{*}{ MMA sample } & \multicolumn{2}{c}{$y$-polarized wave } & \multicolumn{2}{c}{$x$-polarized wave } \\
\hline 1 & $f_{\mathrm{r}} / \mathrm{THz}$ & $A / \mathrm{a} . \mathrm{u}$. & $f_{\mathrm{r}} / \mathrm{THz}$ & 0.42 \\
2 & 0.99 & 0.377 & 0.38 & 0.492 \\
3 & 0.89 & 0.338 & 0.35 & 0.466 \\
4 & 0.8 & 0.318 & 0.32 & 0.444 \\
5 & 0.75 & 0.279 & 0.29 & 0.407 \\
\hline
\end{tabular}

In the simulation results, it can be noted that the resonant frequency red-shifts proportionally to the geometric parameters increase, due to the higher inductivity of the ERR. The MMA sample 1 presents the best absorptance, with the value of 0.549 . These values are going to be considered optimal and will be used as a reference in the next steps of evaluation.

After irradiation at $418 \mu \mathrm{m}$ wavelength ( $0.72 \mathrm{THz})$ there was disturbance of the cell adhesion to surface in $70 \%-80 \%$ of neurons ${ }^{[16]}$, after irradiation at $337-\mu \mathrm{m}$ wavelength $(0.89 \mathrm{THz})$ and intensity of $400 \mu \mathrm{W} / \mathrm{cm}^{2}$ there was a growth of tumor $^{[17]}$, so the samples 2 and 4 show peak of absorptance at these frequencies, moreover we show the possibility to change a resonant frequency by the ERR geometric parameters changing.

\subsection{Influence of the spacer thickness}

There are 2 types of resonances in this frequen- cy range: magnetic and electric (in this paper they are indicated as LC-mode and plasmonic resonance, respectively). We have the optimized parameters for the plasmonic resonance, due to its resonant frequencies closer to the destructive frequencies for the biological objects. That is why we concentrate more attention on the ERR geometric parameters, because of its influence on plasmonic resonance is much stronger than that of spacer thickness.

To illustrate the effect of the spacer thickness, the parametric sweep was performed in the range from 5 to $35 \mu \mathrm{m}$ for the sample 1 in Tab. 2(because this sample shows maximal absorption). The theoretical values of absorptance and Q-factor of the sample 1 were obtained and are presented in Fig. 4(the resonant frequency is barely the same as that in Tab. 3 , because the resonant frequency is determined by the ERR geometric parameters, and the dielectric layer thickness influence on the resonant 
frequency is neglected low).



(a)

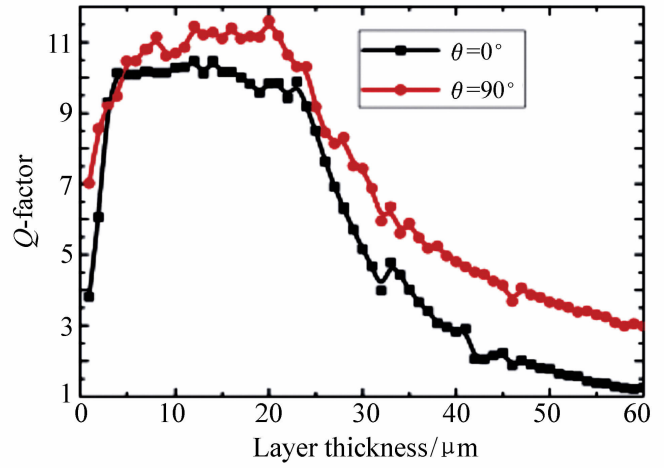

(b)

Fig. 4 Influence of the polyimide SU-8 layer thickness on the resonant peak absorptance(a) and on the Q-factor(b) for the sample 1 with the ERR layer thickness of $0.5 \mu \mathrm{m}$

In these results, we obtained the optimal value of the spacer layer thickness of $21.6 \mu \mathrm{m}$. The sample 1, with the optimal thickness presents the best resonant absorptance. Its value is higher than $90 \%$

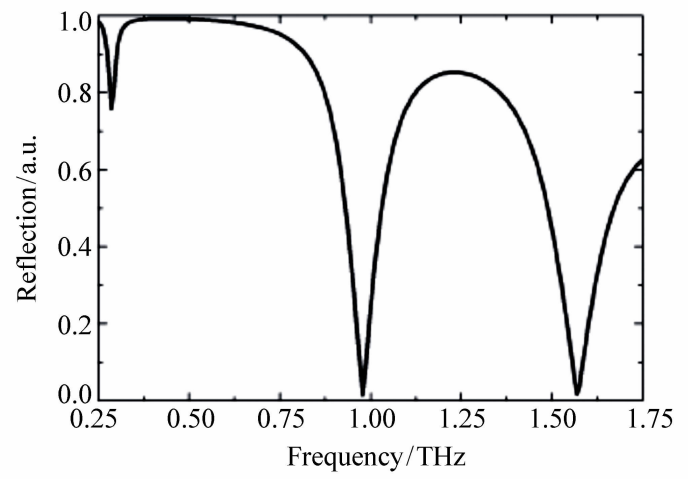

(a) for $y$-polarized wave, ensuring a narrowband resonant peak. Fig. 5 presents the absorptance of the structure with the optimized spacer thickness for both wave polarizations.

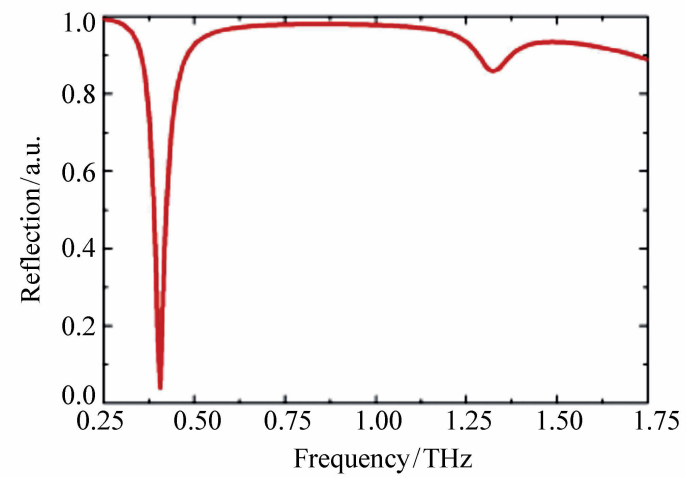

(b)

Fig. 5 Spectral characteristics of the Sample 1 with the optimized spacer thickness for $y$-polarized(a) and $x$-polarized(b) waves

The optimal thickness of the dielectric layer is determined by the equation $t=\frac{\lambda_{\text {res }}}{4 n_{\text {eff }}}$, where $t$ is the dielectric layer thickness, $\lambda_{\text {res }}$ is the resonant frequency, $n_{\text {eff }}$ is the effective refractive index of the dielectric layer covered by the ERR array. For example the optimal spacer thickness for the sample 1 could be calculated using the following data: for $y$ polarized wave, $\lambda_{\text {res }}=303 \mu \mathrm{m}\left(\nu_{\text {res }}=0.99 \mathrm{THz}\right)$, $n_{\text {eff }} \sim 3.9$; for $x$-polarized wave, $\lambda_{\text {res }}=713 \mu \mathrm{m}$ $\left(\nu_{\text {res }}=0.42 \mathrm{THz}\right), n_{\text {eff }} \sim 8$. So the optimal spacer thickness for both polarizations is $t \approx 21.6 \mu \mathrm{m}$. There is the dispersion of the metasurface effective refractive index in this frequency range. The dispersion could be calculated by the method given in Ref. [18].

Next, we obtained and evaluated the $E$-field distribution in the MMA at the resonant frequencies for $y$-polarized wave: $0.292 \mathrm{THz}, 0.969 \mathrm{THz}$ and 1. $623 \mathrm{THz}$ ( Fig. 6 ); and for $x$-polarized wave: 
0. $398 \mathrm{THz}$ and $1.322 \mathrm{THz}$ (Fig. 7 ).



Fig. 6 E-field distribution in MMA samples for $y$-polarized wave at the frequencies:0.292 $\mathrm{THz}(\mathrm{a}), 0.969 \mathrm{THz}(\mathrm{b})$ and 1. $623 \mathrm{THz}(\mathrm{c})$ for the sample 1 with the optimized spacer thickness and the ERR layer thickness of $0.5 \mu \mathrm{m}$

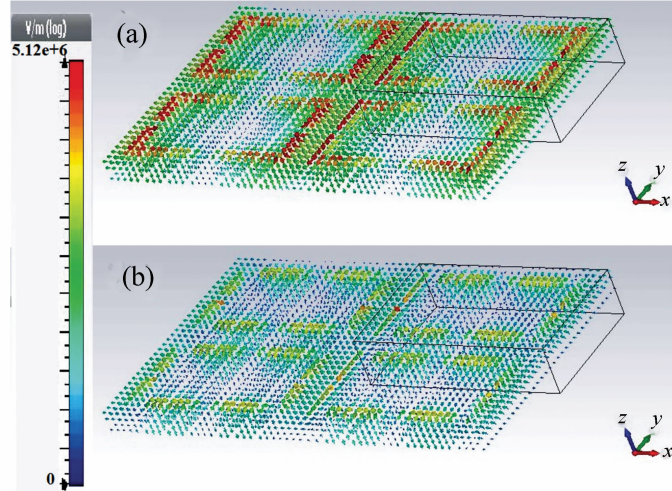

Fig. $7 \quad E$-field vector distribution in the MMA samples for $x$-polarized wave at the frequencies: 0.398 $\mathrm{THz}(\mathrm{a})$ and $1.322 \mathrm{THz}(\mathrm{b})$ for the sample 1 with the spacer layer thickness of $23 \mu \mathrm{m}$ and the ERR layer thickness of $0.5 \mu \mathrm{m}$

These results for the y-polarized wave ( Fig. 6 ) lead to conclude that the resonance at $0.292 \mathrm{THz}$ corresponds to the LC-mode, due to the $E$-field concentrating in the ERR gap; while the resonances at $0.969 \mathrm{THz}$ and $1.623 \mathrm{THz}$ correspond to the plasmonic resonance, due to the $E$-field concentration along ERR borders. For case of $x$-polarized wave in Fig. 7 , the resonances at both frequencies $(0.398$ $\mathrm{THz}$ and $1.322 \mathrm{THz}$ ) correspond to the plasmonic resonance, because of the $E$-field concentrating along each of ERR rings.

The highest absorptance in both cases ( $x$-polar- ized and $y$-polarized waves ) corresponds to the first plasmonic resonance. For this reason we will focus in the absorptance and Q-factor at this resonant peak.

\subsection{Analysis of the ERR thickness}

In order to have the maximum absorptance value, the ERR thickness should be more than the skin depth, as expressed in Eq. (4) :

$$
\Delta=c \sqrt{2 \frac{\varepsilon_{0}}{\omega \mu_{\mathrm{m}}} \rho},
$$

where $\Delta$ is a skin depth; $\mu_{\mathrm{m}}$ is the relative permeability of the copper; $\rho$ is the copper resistivity. The skin depth at the resonant frequency is $\Delta=$ $0.13 \mu \mathrm{m}$.

Since the ERR thickness has to be larger than the skin depth, we selected the range from $0.2 \mu \mathrm{m}$ to $1 \mu \mathrm{m}$ to simulate and evaluate the influence of the ERR thickness. The results can be observed in Fig. 8 , in both terms of the reflection and the Q-factor of the metasurface.

In the case of $y$-polarized wave, the ERR can be considered as a waveguide, so the enlargement of the ERR thickness represents the increasing of the waveguide length. This effect creates the proportional dependence of the MMA absorptance on the ERR layer thickness. On the other hand, for $x$-polarized wave, the ERR will behave as a waveguide with a bend section. It can be observed that after the peak 
at $0.35 \mu \mathrm{m}$ in thickness, losses at the bend section

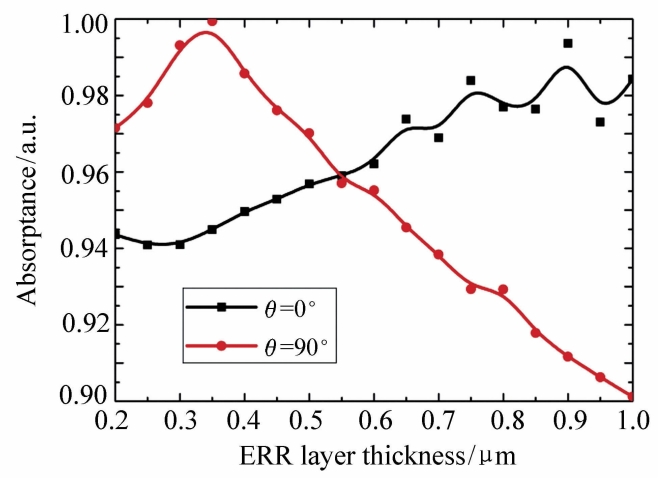

(a) reduce absorptance.

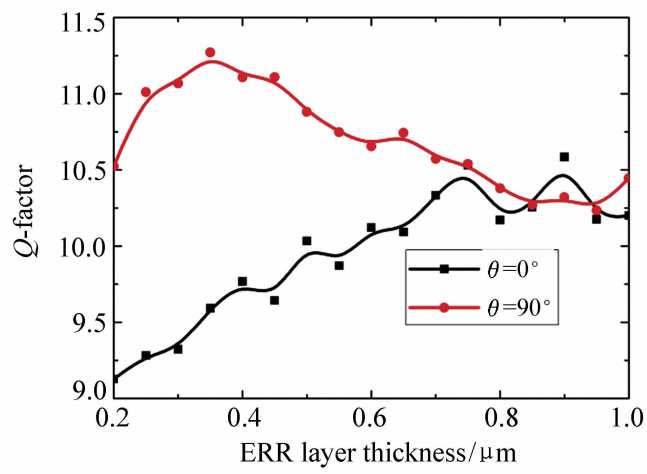

(b)

Fig. 8 Influence of the ERR layer thickness on the resonant peak absorptance(a) and on Q-factor(b) for the sample 1 with the polyimide layer thickness of $23 \mu \mathrm{m}$

The optimal value of the ERR thickness was $0.55 \mu \mathrm{m}$, achieving the absorptance higher than $95 \%$ for both polarizations.

\subsection{Final implementation}

Once the values of thickness were obtained for the different layers, the ERR geometrical values were optimized to achieve the maximum value of ab- sorptance at the resonant frequency. In order to test two different resonance frequencies, the optimized versions of all 5 samples were fabricated. For the samples 1 and 4 (the experimental samples a and b respectively, they have the best fabrication accuracy) shown in Fig. 10, their final values are presented in Tab. 4.

Tab. 4 Geometric parameters for the fabricated MMA

\begin{tabular}{cccccc}
\hline MMA samples & $a / \mu \mathrm{m}$ & $b / \mu \mathrm{m}$ & $p / \mu \mathrm{m}$ & $g / \mu \mathrm{m}$ & $w / \mu \mathrm{m}$ \\
\hline $\mathrm{a}$ & 159 & 78 & 13 & 17 & 5 \\
$\mathrm{~b}$ & 208 & 98 & 13 & 23 & 6 \\
\hline
\end{tabular}

\section{Fabrication process}

The ERR metasurfaces were fabricated using vacuum evaporation and photolithography. The emulsion photomask and the experimental sample were manufactured in the "Vavilov State Optical Institute”. The manufacturing process is shown in Fig. 9, consisting of five steps: (1) a thin layer of chrome and a copper layer were placed on the silicon substrate, using the ion-vacuum spattering method; (2) the liquid polyimide solution ( SU-8) was sputtered using a centrifuge force; (3) the photoresist layer was applied with the centrifuge force, forming the image; (4) the second copper layer was placed to use for the ERRs; and finally (5), the photoresist layer was deleted.



Fig. 9 Five steps of the fabrication of the MMA sample

At the end of the fabrication process, the two MMA samples were obtained with the optimized geometric parameters in Tab. 4, and the optimal thickness for the $\operatorname{ERR}(0.55 \mu \mathrm{m})$ and the polyimide SU- 


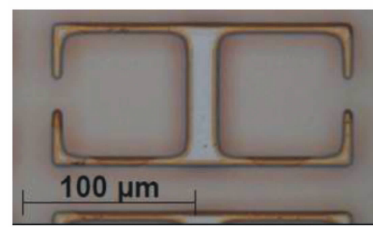

(a)



(b)
Fig. 10 Fabricated MMA samples: (a ) Sample a and ( b ) sample b

8(22.5 $\mu \mathrm{m})$ layers. Fig. 10 shows the MMA unit cell microimages with the standard $100 \mu \mathrm{m}$ bar.

\section{$5 \quad$ Experimental setup}

To test the performance of the designed MMAs, we used the compact TPS (terahertz pulsed spectroscopy) setup ${ }^{[15]}$. Fig. 11 presents the experimental setup and illustrates the TPS waveform detection process. The setup uses the second harmonic of the Er-doped femtosecond fiber laser for both generation and detection of $\mathrm{THz}$ pulses. The laser has the average power of $200 \mathrm{~mW}$. The system uses the central wavelength of $780 \mathrm{~nm}$ and the pulse duration of $100 \mathrm{fs}$. The generation of the THz-wave is performed in a LT-GaAs photoconductive antenna(PCA), and the $\mathrm{THz}$ pulses detection is conducted in a $\mathrm{ZnSe}$ electro-optical detector. The setup operates in the reflection mode with a beam splitter, making the incidence radiation perpendicular to the sample. The measures are performed in the frequency range from 0.25 to $1.75 \mathrm{THz}$.

The reflectivity of the metasurface was determined using Eq. (5) :

$$
R(\nu)=\left|\frac{E_{\mathrm{s}}(\nu)}{E_{\mathrm{r}}(\nu)}\right|^{2},
$$

where $E_{\mathrm{r}}$ is the fourier-domain representation of the reference waveform $E_{\mathrm{r}}=E_{\mathrm{r}}(t)$, reflected from the plane gold mirror placed behind the rigidly fixed diaphragm, and $E_{\mathrm{s}}$ is the fourier-domain representation of the sample waveform $E_{\mathrm{s}}=E_{\mathrm{s}}(t)$, reflected from the sample of interest placed behind of diaphragm.

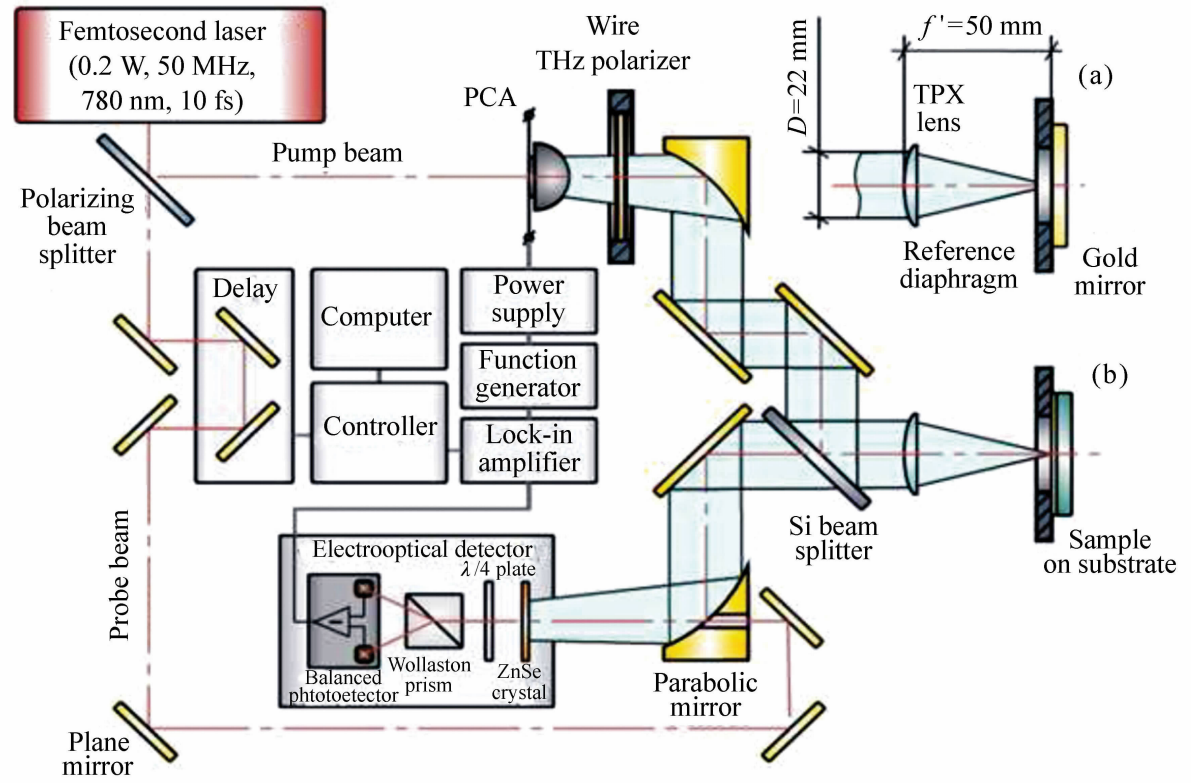

Fig. 11 Design of reflective $\mathrm{THz}$ spectrometer

\section{Results and discussion}

of two metasurfaces was obtained both theoretical and experimentally, these results can be found in Fig. 12 and Fig. 13, respectively.

In order to validate the results, the performance 


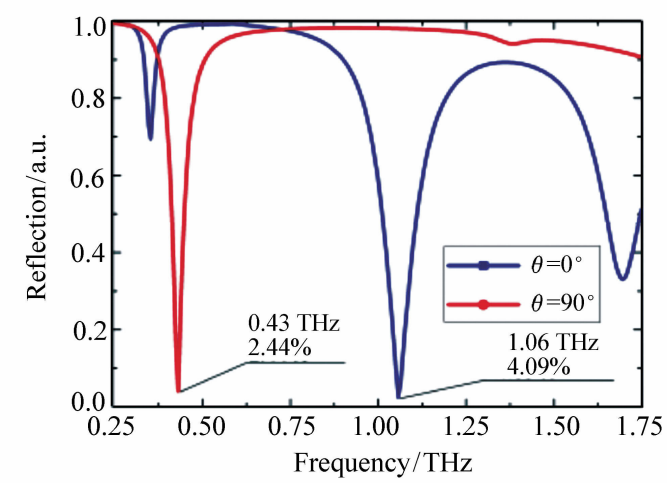

(a)

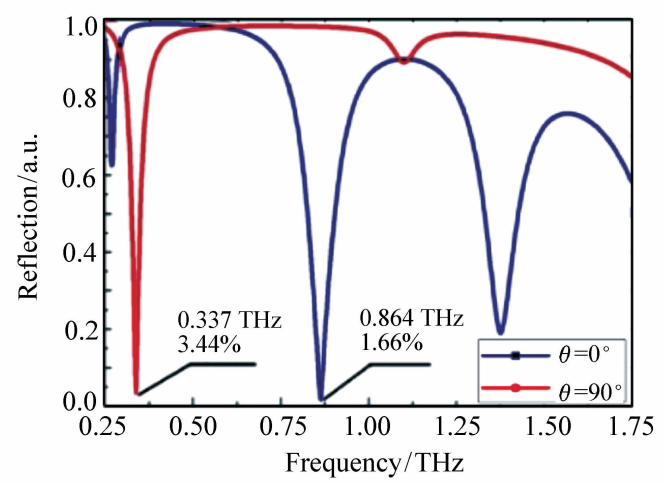

(b)

Fig. 12 Simulated reflection coefficient of samples a (a) and $\mathrm{b}(\mathrm{b})$ for $x$-polarized wave $\left(\theta=90^{\circ}\right)$ and $y$-polarized wave $\left(\theta=0^{\circ}\right)$


Fig. 13 Reflection coefficient of the two experimental MMA samples for $y$-polarized ( solid curve) and $x$-polarized(dotted curve). The geometric parameters of the samples are indicated above in Fig. 10

The theoretical absorption values for the sample (a) are $95.91 \%$ at the frequency of $1.06 \mathrm{THz}$ for $y$-polarized wave and $97.56 \%$ at the frequency of $0.43 \mathrm{THz}$ for $x$-polarized wave; and for the sample (b) $98.34 \%$ at the frequency of $0.864 \mathrm{THz}$ for $y$ polarized wave, $96.56 \%$ at the frequency of $0.337 \mathrm{THz}$ for $x$-polarized wave.

The reflection was measured for the fabricated MMA samples, to obtain the absorptance of each sample. For the sample (a) the results demonstrate the total absorption of $99.57 \%$ at the frequency of $1.06 \mathrm{THz}$ for $y$-polarized wave and $99.11 \%$ at the frequency of $0.4 \mathrm{THz}$ for $x$-polarized wave; for sample (b) the measured absorptance is $99.98 \%$ at the frequency of $0.87 \mathrm{THz}$ for y-polarized wave and $98.68 \%$ at the frequency of $0.33 \mathrm{THz}$ for $x$-polarized wave.

As it can be seen, the overall performance from the simulation and the measured samples are very similar. The resonant frequencies are close to the ones obtained in the simulation, and all the curves present the same performance. Moreover, the experimental results appear to outperform the simulated peaks of absorptance. The differences between theoretical and experimental results can be explained by the variation of material parameters from tabular values and by tolerances of the fabrication process.

\section{Conclusions}

In this paper, we analyzed the effects of the geometric characteristics of the narrowband absorber for $\mathrm{THz}$ frequencies. The structure consisted of a unit cell based on electrical ring resonators. The performance of the MMA was analyzed using the FDFD method, in order to obtain the values of the ERR geometrical parameters, the spacer thickness and the ERR thickness resulting in maximum absorptance. 
We showed that the perfect narrowband absorber can be formed by using Electrical Ring Resonator metasurface at terahertz frequencies. The resonance peaks with absorptance more than $99 \%$ were obtained under normal incidence (the absorptance of $99.57 \%$ at $1.06 \mathrm{THz}$ for $y$-polarized wave and $99.11 \%$ at $0.4 \mathrm{THz}$ for $x$-polarized wave). This structure is polarization sensitive : changing of polarization angle leads to shift of resonant peak frequency and change of resonant peak absorptance.
These results not only serve as a guideline for future designs and metamaterial structures based on ERR, but also show the validity of the proposed structures in the implementation of different hardware components for $\mathrm{THz}$ systems.

\section{Acknowledgements}

This work was financially supported by Government of Russian Federation, Grant 074-U01.

\section{参考文献：}

[1] KUZNETSOV S A,PAULISH A G, GELFAND A V , et al. . Matrix structure of metamaterial absorbers for multispectral terahertz imaging $[\mathrm{J}]$. Progress In Electromagnetics Research,2012,122:93-103.

[2] HU T, LANDY N I, BINGHAM C M, et al. . A metamaterial absorber for the terahertz regime: design, fabrication and characterization[J]. Optics Express, 2008,16(10):7181-7188.

[3] LANDY N I, SAJUYIGBe S, MOCK J J, et al. . Perfect metamaterial absorber [J]. Physical Review Letters, 2008, 100 (20): 207402 .

[4] WEN Q Y,XIE Y S,ZHANG H W, et al. . Transmission line model and fields analysis of metamaterial absorber in the terahertz band[J]. Optics Express,2009,17(22):20256-20265.

[5] HU T, BINGHAM C M,STRIKWERDA A C, et al. . Highly flexible wide angle of incidence terahertz metamaterial absorber: design, fabrication, and characterization[J]. Physical Review B,2008,78(24):241103.

[6] LANDY N I,BINGHAM C M,TYLER T, et al. . Design, theory, and measurement of a polarization-insensitive absorber for terahertz imaging $[\mathrm{J}]$. Physical Review $B, 2009,79(12): 125104$.

[7] YE YUQIAN, YI JIN, SAILING HE. Omni-directional, broadband and polarization-insensitive thin absorber in the terahertz regime[J]. Journal of the Optical Society of America B,2009,27(3) :498-504.

[8] SHCHEGOLKOV D Y,AZAD A K, O'HARA J F, et al. . Perfect subwavelength fishnetlike metamaterial-based film terahertz absorbers [J]. Physical Review B,2010,82(20):205117.

[9] HU T,BINGHAM C M,PILON D, et al. . A dual band terahertz metamaterial absorber[J]. Journal of Physics D:Applied Physics ,2010,43(22):225102.

[10 ] SHEN X P, CUI T J,ZHAO J M, et al. . Polarization-independent wide-angle triple-band metamaterial absorber[J]. Optics Express,2011,19(10):9401-9407.

[11] GRANT J, MA Y,SAHA S, et al. . Polarization insensitive, broadband terahertz metamaterial absorber[J]. Optics Letters $, 2011,36(17): 3476-3478$.

[12] WANG B X,ZHAI X, WANG G Z,et al. . A novel dual-band terahertz metamaterial absorber for a sensor application [J]. Journal of Applied Physics,2015,117(1):014504.

[13] ALBANI M,BERNARDI P. A numerical method based on the discretization of maxwell equations in integral form, short papers) [J]. IEEE Transactions on Microwave Theory and Techniques, 1974,22(4) :446-450.

[14] NOVOTNY L,HECHT B. Principles of Nano-optics[M]. London:Cambridge University Press,2012.

[15] ZAITSEV K I,CHERNOMYRDIN N V,KUDRIN K G, et al. . Terahertz spectroscopy of pigmentary skin nevi in vivo[J]. Optics and Spectroscopy,2015,119(3):404-410.

[16] OLSHEVSKAYA J S, RATUSHNYAK A S, PETROV A K, et al. . Effect of terahertz electromagnetic waves on neurons systems[C]. IEEE Region 8 International Conference on Computational Technologies in Electrical and Electronics Engineering, SIBIRCON 2008. IEEE, 2008, DOI: 10. 1109/SIBIRCON. 2008. 4602607. 
[17] KISELIOV V K, MAKOLINETS V I, MITRYAEVA N A, et al. . Application of terahertz lasers setup for the investigation of the influence of HHF-radiation on the tumor processes[C]. 37th International Conference on Infrared, Millimeter, and Terahertz Waves (IRMMW-THz), IEEE,2012:1-2.

[18 ] CHEN X D, GRZEGORCZTK T M, WU B I, et al. . Robust method to retrieve the constitutive effective parameters of metamaterials [J]. Physical Review E,2004,70(1):016608.

\section{作者简介：}

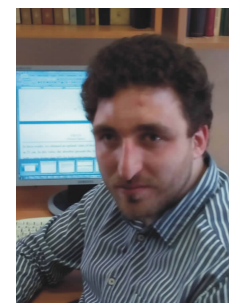

GOMON Daniel ( 1989-), Ph. D. student of Photonics and Optical Information Technology Department, ITMO University. His research interests are on numerical modeling and simulation of metasurfaces for $\mathrm{THz}$ frequency range. E-mail: GomonDA89@ya.ru

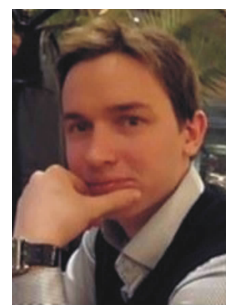
KHODZITSKY Mikhail (1984-), Chief of Terahertz Biomedicine Laboratory, Associate professor, Department of Photonics and Optical Information Technology, ITMO University, Russia. His research interests are on terahertz photonics, metamaterials, biophotonics and terahertz spectroscopy. E-mail: khodzitskiy@yandex. ru

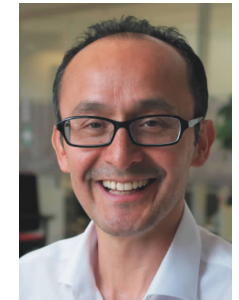

Tafur Monroy Idelfonso(1968-), Professor of Photonics Systems, Department of Electrical Engineering, and Director of Photonics Systems at the Photonic Integration Technology Center, Eindhoven University of Technology. His research interests are in Photonics technologies for Terahertz systems for communications, sensing and imaging. E-mail: i. tafur. monroy@ tue. $\mathrm{nl}$ 